\title{
TRIBUNALES CONSTITUCIONALES: DINAMIZADORES EN LA CONSTRUCCIÓN DE LA DEMOCRACIA CONTEMPORÁNEA PARA JOHN RAWLS*
}

\author{
CONSTITUTIONAL COURTS: DYNAMIZERS IN THE \\ CONSTRUCTION OF CONTEMPORANY DEMOCRACY \\ FOR JOHN RAWLS
}

\author{
John Fernando RESTREPO TAMAYO
}

RESUMEN: El siguiente texto tiene la intención de presentar cómo responde John Rawls a un debate propio de la filosofía política y el derecho constitucional contemporáneos a propósito del ascenso de los tribunales constitucionales con revisión judicial en el escenario político y jurídico de sociedades complejas que sufrieron cambios estructurales después de la segunda guerra mundial. El debate se debe a que algunos consideran que los tribunales constitucionales son una fachada de democracia. Un verdadero obstáculo de la construcción del poder público popular. Para otros, representan el merecido lugar de equilibrio para sopesar el poder que ostentan peligrosamente bien sea el Ejecutivo o el Legislativo. ¿En qué lugar del péndulo se encuentra John Rawls? Este texto pretende responderse a esa pregunta.

Palabras clave: Filosofía política contemporánea, derecho constitucional, mundo de la posguerra, tribunales constitucionales con revisión judicial, obstáculo de democracia, promoción de minorías.
ABSTRACT: The following text has the intention to show how John Rawls responds to a debate of the political philosophy and the contemporary constitutional right regarding to the promotion of constitutional courts with judicial review in the political and legal scene of hard societies that suffered estructural changes after World War II. The debate is because some people consider that the constitutional courts are a facade of democracy. A real obstacle of the construction of the popular public power. For other people, they represent the deserved place of balance to maintain the power that show dangerously either the executive or the legislature. ¿In what place of the pendulum is John Rawls? This text seeks to answer that question.

Descriptors: Contemporary Political Philosophy, Constitutional Right, World of Postwar, Constitutional Courts with Judicial Review, Obstacle of Democracy, Promotion of Minorities.

* Este artículo es un avance del trabajo de grado para aspirar al título de magíster en filosofía política por el Instituto de Filosofía de la Universidad de Antioquia, Colombia.. 


\section{INTRODUCCIÓN}

Si bien es cierto que John Rawls en Liberalismo político (1993) pretende ofrecer un texto donde responde al conjunto de refutaciones que recibió por Teoría de la justicia (1971) y que su interés central es mostrar de qué manera un consenso entrecruzado sobre una concepción política de justicia en sociedades liberales y democráticas puede permitirle a los asociados que profesan disímiles creencias políticas, religiosas, económicas o culturales llevar una vida buena al interior de una sociedad estable, duradera y pluralista. También es cierto que se aborda en la Conferencia VI de Liberalismo político un aspecto de suma relevancia para la teoría política y el derecho constitucional actuales. Un asunto que si bien por la lógica de su redacción está incluido de una manera articulada y sistemática para responder al interés central de la obra, encara el desarrollo de toda una discusión que en este texto vamos a tratar de manera autónoma y en un contexto específico. Esto es: ¿cuál es el lugar y las funciones del Tribunal Constitucional en la teoría política de John Rawls?

Para llevar a buen término el desarrollo de esta pregunta tendremos que considerar: (i) el ascenso del Tribunal Constitucional y el acto de revisión judicial como ruptura del modelo político moderno; (ii) la problematización del ascenso del Tribunal Constitucional en la nueva configuración del poder público; (iii) la posición de John Rawls: lugar y funciones del Tribunal Constitucional en la idea de razón pública.

\section{EL ASCENSO DEL TRIBUNAL CONSTITUCIONAL Y EL ACTO DE REVISIÓN JUDICIAL COMO RUPTURA DEL MODELO POLÍTICO MODERNO}

La construcción política moderna puede explicarse como crítica al ejercicio autocrático y clerical del poder público que funcionó a lo largo de la Edad Media. ${ }^{1}$ En manos de unos cuantos estaba el monopolio del

1 Se ha denominado Edad Media (473 dC-1492 dC) al periodo milenario que oscila entre el mundo antiguo y el mundo moderno. Caracterizado fundamentalmente por una marcada influencia de la Iglesia católica romana. La concepción cristocéntrica de la historia fue transversal al discurso político, moral, económico y cultural de la época. Fue un periodo donde la expansión religiosa trazada por los jerarcas católicos permitió una autoridad política y religiosa vertical-descendente. El poder reposaba en la autoridad religiosa 
poder político, económico, cultural y espiritual. La exigencia burguesa, ilustrada y racional dio al traste ese modelo milenario y trazó una nueva ruta política donde la mayoría parlamentaria, representando los intereses del pueblo, estaba legitimada para regir el nuevo curso de la historia. La filosofía política moderna describe cómo los individuos en aras de garantizar una estabilidad material y dejar de lado la zozobra y el riesgo que implica el estado de naturaleza confieren libertades a un tercero llamado Estado civil para que sus derechos naturales sean efectivamente respetados. La práctica política burguesa, para lograr la instauración del Estado, regido por un texto escrito constitucional, donde queden consagrados los derechos civiles y políticos tendrá que ir hasta las últimas consecuencias y dejar en la plaza pública la cabeza guillotinada del rey.

Con las revoluciones liberales y el ascenso al poder de la burguesía a finales del siglo XVIII se instaura un discurso político con el cual se representa toda una época y sirve de sustento a la nueva manera de entender tanto la historia como el ejercicio del poder público. Se instaura el Estado de derecho, la república democrática, la democracia representativa, la soberanía nacional, la mayoría parlamentaria, el principio de legalidad y la convicción de que la estabilidad de dicho sistema reposa en el ejercicio restrictivo de tres ramas del poder público: Ejecutivo, Legislativo y Judicial. ${ }^{2}$ Cada una con funciones específicas y confiadas en las ideas de que el control recíproco es posible y el pueblo, representado en el Parlamento, es el soberano.

En esta concepción moderna de tridivisión de poderes, el Ejecutivo y el Legislativo gozan de un enorme protagonismo. Son elegidos directamente por el pueblo. La función del legislador es hacer la ley. Excepcionalmente el Ejecutivo también tiene acceso a esa facultad legislativa mediante decretos. El Poder Judicial tiene la función de hacer cumplir la ley. Debe someterse literalmente a las disposiciones hechas por el legis-

y de esta manera el disenso y la crítica a la administración del poder público era algo asociado con la herejía. Soto Posada, Gonzalo, Diez aproximaciones al Medioevo, Medellín, UPB, 1999.

2 Este diseño tripartito lo hereda la política moderna del modo de organización de la República romana (510 aC-27 aC). Había en la configuración política de aquella época un pretor, un senado consulto y una asamblea. Cada institución tenía funciones específicas con respecto a la organización de la asociación política. Entre ellas se ejercía un control recíproco en aras de evitar los excesos derivados del uso del poder. 
lador. ${ }^{3}$ Sus decisiones sólo son vinculantes para las partes y jamás la sentencia de un juez podrá tener efectos vinculantes sobre la decisión de otro juez. El desarrollo jurídico está sujeto a un ejercicio silogístico del juez y es así como se entiende la seguridad jurídica y la estabilidad política. $^{4}$

Pero los presupuestos teóricos de este modelo político moderno duraron poco más de un siglo. En la primera mitad del siglo XX hubo una cadena sucesiva de acontecimientos de suma relevancia como el triunfo de los bolcheviques en Rusia; la crisis del modelo capitalista con el crack en 1929, pueblos ricos expuestos a condiciones de miseria; el ascenso de regímenes totalitarios revestidos de democracia y legitimidad; Europa como epicentro de la gran guerra. Todos los actos de barbarie de la segunda guerra mundial, que fueron política de Estado, no han podido ofrecer una justificación razonable. Los hechos históricos y tangibles han permitido concluir que el modelo político de la tridivisión de poderes no logró mantener la balanza de pesos y contrapesos en equilibrio.

El precio que pagó la humanidad por confiar en lo infalible de las mayorías y en la legalidad del gobernante como representante del espíritu del pueblo, desgastó notablemente el poder ilimitado de las mayorías parlamentarias y en esa medida el visor de la teoría política y el derecho constitucional creyó oportuno que el Poder Judicial estaba llamado a ocupar un lugar protagónico en el escenario jurídico político. ${ }^{5}$ Se le asig-

3 El artículo 230 de la Constitución Política de Colombia reza así: "Los jueces en sus providencias, sólo están sometidos al imperio de la ley. La equidad, la jurisprudencia, los principios generales del derecho y la doctrina son criterios auxiliares de la actividad judicial".

4 La aplicación silogística del derecho: Premisa Mayor: Norma. Premisa menor: hecho. Conclusión: sentencia; ha gozado de gran estímulo para la percepción positivista decimonónica del derecho en tanto se concluye que toda decisión judicial esté exenta de valoraciones morales, políticas, culturales. Las decisiones judiciales encierran la plenitud del sistema jurídico porque el juez solo se basa en la norma. Otra virtud de este modelo es que permite prever la decisión judicial. El juez no interpreta la norma. Simplemente la aplica y la norma a aplicar es sólo una. Toda decisión judicial basada en derecho ofrece a la comunidad en general la confianza necesaria para comprender por qué el derecho es el mejor y más óptimo instrumento de cohesión social.

5 El profesor Gustavo Zagrebelsky amplía esta idea explicándola como un cambio de paradigma. El punto de partida lo encontramos en los acontecimientos de la segunda guerra mundial. El modelo decimonónico establece una organización social llamada Estado de derecho. En él se pensaba el derecho mediante reglas, emanadas del legislador. 
nó al tribunal constitucional el papel de guardián de la Constitución, donde aparecen consagrados derechos básicos e instrumentos materiales de representación y participación políticas para que estén al alcance de todos (mayorías y minorías) y de esa manera permitirle a la democracia adquirir una connotación distinta a aquella que por confiar en la voz de las mayorías se permitió la eliminación sistemática de una minoría, que en el caso concreto hacía las veces de la humanidad entera. Queda como potestad del Tribunal Constitucional a través de la revisión judicial servir de filtro entre las decisiones del Parlamento, los intereses del Ejecutivo y el pueblo. ${ }^{6}$ La revisión judicial es un ejercicio de control jurídico y político mediante el cual el Tribunal Constitucional se asegura de que ningún proyecto normativo sea incorporado al ordenamiento jurídico, si a su juicio, dicho proyecto contradice el espíritu de la Constitución. O poder de excluir del ordenamiento jurídico una norma existente que en el ejercicio interpretativo del Tribunal Constitucional resulte contradictoria con el espíritu del texto escrito constitucional. ${ }^{7}$

Y el ejercicio jurídico emanaba del silogismo lógico positivo. El juez aplica el derecho y así se garantiza la seguridad jurídica. Las reflexiones jurídico-políticas posteriores a la segunda guerra mundial tanto en Italia como en Alemania permitieron trazar en la organización jurídico política del Estado social de derecho una nueva interpretación de los textos escritos constitucionales que permiten pensar el derecho por principios y de esta manera se le ha reducido al legislador el rótulo de señor del derecho por señor de las reglas. El juez ahora, en el marco del derecho por principios pasa a ser creador de derecho. Zagrebelsky, Gustavo, El derecho dúctil. Ley, derechos, justicia, 3a. ed., Madrid, Trotta, 1999.

6 En su texto, La Constitución como norma y el Tribunal Constitucional, Eduardo García de Enterría señala que la judicial review es un legado típicamente inserto en la cultura jurídica norteamericana, que se ha ido explayando de una manera sobresaliente. Señala enfáticamente que en el ejercicio de revisión de los tribunales constitucionales se juegan las posibilidades y el futuro mismo del texto escrito constitucional. "El tema del Tribunal Constitucional es posiblemente el tema central de nuestra Constitución", Madrid, Civitas, 2001.

7 Un elemento paradigmático de este presupuesto lo encontramos en la sentencia Marbury vs. Madison (1803) donde el juez Marshall se enfrenta al siguiente análisis en el que está en disputa una ley con la Constitución: al aplicarse la norma se desconoce la Constitución. Al aplicarse la Constitución debe desconocerse la norma. El juez Marshall opta por la segunda opción. En esa medida sienta un precedente en el cual se posibilita a la acción judicial la potestad de desconocer una norma y así evitar que se ponga en riesgo la prevalencia de la Constitución. 


\section{LA PROBLEMATIZACIÓN DEL ASCENSO DEL TRIBUNAL CONSTITUCIONAL EN LA NUEVA CONFIGURACIÓN \\ DEL PODER POLÍTICO}

El hecho de que debido a la revisión judicial el Tribunal Constitucional sea el filtro entre las prescripciones del legislador y el pueblo, además de exclusivo intérprete del texto constitucional ha generado un debate en el escenario de la filosofía política y el derecho constitucional acerca de la legitimidad de este órgano que resulta ser no sólo minoritario sino también un cuerpo técnico no elegido directamente por el pueblo. Frente al ascenso del Poder Judicial hay dos posiciones críticas que sirven como clave de lectura para aproximarnos a la discusión. Una posición que aprueba y otra que rechaza el ascenso del Poder Judicial.

Los argumentos que ofrece la primera posición para concebir dicho ascenso como un aspecto benévolo son:

1. El Tribunal Constitucional es el órgano que decide efectivamente. Pone el dedo en la llaga en asuntos álgidos del debate político. Esto se debe a que el Legislativo y el Ejecutivo en tanto elegidos directamente por el pueblo tienen el limitante de no afrontar abiertamente aspectos cruciales del destino político porque temen poner en riesgo su caudal electoral. Su posición en la arena política es problemática y eso hace que su comportamiento a la hora de decidir tienda a ser tan ambiguo que en últimas están y no están de acuerdo a la vez sobre algún asunto a decidir. De las tres ramas del poder público la más autónoma es la judicial.

2. El Tribunal Constitucional ha permitido la reivindicación de derechos de grupos minoritarios permitiendo además su inclusión en el escenario político. John Hart Ely 8 explica que la principal función del Tribunal Constitucional es mantener abiertos los canales de participación de todos los agentes sociales. Así tienen cabida grupos minoritarios. No es que el Tribunal Constitucional obligue a las minorías a que par-

En esta misma dirección encontramos los artículos 140-142 de la Constitución de Austria de 1920. Artículo 93 de la Ley Fundamental de la República Federal de Alemania de 1949. Artículo 241 de la Constitución Política de 1991

8 Ely, John Hart, Democracia y desconfianza, Bogotá, Siglo del Hombre Editores, 1997. 
ticipen políticamente; lo cual sería una negación del espíritu de la democracia donde la participación es libre. Su papel es ofrecer garantías para que todos los asociados sientan confianza para intervenir en asuntos públicos.

3. El Tribunal Constitucional ha limitado a la democracia de sus propios excesos. ${ }^{9}$ Representados por los intereses de las mayorías. Por eso se entiende que quien ejerce el límite no puede ser la mayoría misma sino un órgano minoritario que sepa direccionar intereses comunes.

4. El Tribunal Constitucional ha revertido la noción de democracia. Entendida ésta no ya como la voz aplastante de las mayorías sino también donde hay respeto por las minorías.

5. El Tribunal Constitucional sí tiene límites: el texto escrito constitucional; el límite intraorgánico, dado al interior de la misma corporación; y el límite interorgánico, ejercido por órganos externos al Tribunal Constitucional. ${ }^{10}$

6. Los jueces deben motivar sus sentencias. Un juez no puede emitir una sentencia sino a través de un proceso rigurosamente establecido. En ese proceso está la motivación. Un aspecto clave donde el juez debe ofrecer los argumentos lógicos, críticos y sujetos a derecho sobre los cuales se va a sustentar su sentencia. Esta exigencia de debida motivación del juez se amplía a través del principio de publicidad. De manera pues que el juez no emite una sentencia de manera arbitraria. Sus decisiones son confiables porque han de ser consecuencia de un ejercicio analítico, crítico y donde se permite incluso contar con ayuda técnica sobre el asunto particular. Así que cada motivación es una posibilidad que tiene el juez para dinamizar la interdisciplinariedad. ${ }^{11}$

Los contrargumentos y refutaciones que ofrece la segunda corriente para sospechar del ascenso del Tribunal Constitucional son:

9 Esta idea es ampliamente desarrollada por Tom Gisnsburg en Judicial Review in New Democracies: Constitucional Courts in Asian Cases, Cambridge University Press, 2006.

10 A propósito de esta afirmación se recomienda el artículo: "Legitimidad del control constitucional y los controles a la Corte Constitucional del profesor Luis Alfonso Bravo Restrepo", Estudios de Derecho, Medellín, núm. 59, julio-diciembre de 2000, pp. 133 y 134.

11 A propósito de la concepción constitucional del principio de publicidad se recomienda ver la Sentencia C-836 de 2001. 
1. El exceso de poder del Tribunal Constitucional es ilegítimo en una verdadera democracia. Una democracia se soporta en una soberanía popular. Así pues que dada la imposibilidad de que todo el pueblo pueda intervenir en la solución de sus propios asuntos se ha convenido de que se elijan a algunos miembros de la comunidad para tal fin. Aquellos elegidos directamente por el pueblo son voz viva del pueblo mismo y de sus intereses. Así pues que sus propuestas normativas eventualmente pueden estar sujetas a una revisión de forma y nunca de fondo. El ascenso del Poder Judicial se ha desbordado de tal manera que su revisión es no sólo formal sino también material, por lo cual estaría desconociendo el trámite democrático y oponiéndose a la voz del pueblo mismo en cabeza de sus representantes directos.

2. El ascenso del Poder Judicial no reposa en la reivindicación de intereses de grupos marginados sino en la defensa de élites políticas, jurídicas y económicas que ven amenazados sus intereses en las actuales democracias. Esta es la tesis que sostiene Ran Hirschl ${ }^{12}$ después de hacer una revisión a los casos del empoderamiento judicial en Canadá, Israel, Nueva Zelanda y Sudáfrica.

3. Los límites del Tribunal Constitucional por ser indeterminados son una negación de la democracia. Decir que al Tribunal Constitucional lo limita la Constitución misma es decir todo y nada a la vez. La Constitución como carta de navegación en una comunidad política es muy importante pero dada la generalidad de sus prescripciones sólo puede enunciar asuntos generales que posteriormente habrán de aterrizar decretos reglamentarios. Así pues que el carácter incluyente de la norma da lugar a múltiples interpretaciones. De manera pues que la certeza se diluye porque el sentir de la Carta queda expuesto a argucias interpretativas y oportunistas donde un mismo enunciado normativo sirve como argumento para conceder o restringir una esperada acción estatal.

4. Las decisiones judiciales con exceso de discrecionalidad protegen concepciones personalísimas. El juez en tanto ser humano es consecuencia de una serie de valoraciones personales afincadas a lo largo del tiempo. No es dable creer que el juez se pueda desprender de su humanidad y sus convicciones personales, sociales, religiosas o políti-

12 Hirschl, Ran, Towards Juristocracy. The Origins and Consequences of the New Constitucionalism, Harvard University Press, 2004. 
cas para emitir una sentencia. Así pues que la decisión judicial más que representar los intereses de una colectividad popular es una imposición normativa personalísima.

5. Gerald Rosenberg escribe un texto donde amplía el debate en torno a las posiciones que hay con respecto a la acción judicial. Estudia el interior del sistema jurídico-político americano a la luz de dos visiones: (i) Visón de la Corte dinámica y (ii) Visión limitada de la Corte. Los primeros creen que los cambios sociales más relevantes tienen su origen en la decisión judicial. De la sentencia el problema se pone en la agenda política, los medios ejercen presión sobre grupos políticos y surge el cambio. Los segundos tienen una lectura escéptica de este primer relato. Muestra entonces el texto, propio de un método empírico descriptivo, un conjunto de referencias y acontecimientos dados en la historia política estadounidense (segregación racial, aborto, feminismo, medio ambiente, redistribución, sistema penitenciario) para identificar si la reforma social significante se deriva o no de una acción judicial. Además de los hechos referentes acude el autor a estudiar criterios que muestren si puede derivarse un impacto de la decisión judicial en la opinión pública, la cobertura mediática o la movilización de los agentes políticos. Al final: se muestra que los límites y condiciones que ponen los exponentes de la visión limitada de la Corte deben ser resueltos para poder pensar en reformas significantes, pues de lo contrario podemos encontrar que las decisiones están sujetas a factores políticos ajenos al alto tribunal o a la expedición de cambios que aunque efectivamente son cambios, no pasan de ser pequeños cambios. ${ }^{13}$

6. Negación de la discrecionalidad judicial. A juicio de Ronald Dworkin la actividad judicial es inexistente. El juez no crea derecho. Lo aplica. En su auxilio está todo el ordenamiento jurídico basado en reglas y dado que no existe una separación entre derecho y moral, en caso de lagunas o vacíos el juez en lugar de acudir a la discrecionalidad, lo que debe hacer es acudir a los principios. Dworkin, de su famoso debate con Hart, diseña un método inspirado para el juez Hércules, capaz de identificar siempre en los principios aquellos elementos que puedan generar alguna preocupación por vacío alguno. Asimismo critica a

13 Rosenberg, Gerald, The Hollow Hope: Can Courts Bring About Social Change?, Chicago, University of Chicago Press, 1991. 
Hart, quien frente a la textura abierta de precepto normativo supone la discrecionalidad judicial. Para Dworkin este límite no existe porque el juez siempre puede recurrir a presupuesto complementarios de la acción jurídica.

7. Alexander Bickel también expresa su rechazo al poder de la acción judicial por considerarla una fuerza antimayoritaria. Es una expresión que resulta ajena al modelo democrático norteamericano. No puede tolerarse que sea un grupo minoritario intérprete y aplique la Constitución en asuntos de trascendencia política que puede ser contraria a la voluntad del órgano legislativo, a quien el pueblo eligió directamente. Peligroso además que las decisiones judiciales no puedan ser modificadas por el legislador. El exceso de Poder Judicial fragmenta la unidad democrática. ${ }^{14}$

Puede comprenderse entonces que el debate sobre el ascenso del Poder Judicial además de álgido es vigente. Ocupa un puesto central en las discusiones actuales de la filosofía política y el derecho constitucional. Dado que John Rawls también interviene en este debate, vamos a ocuparnos ahora de los argumentos que ofrece sobre el tema y de esta manera dar respuesta a la pregunta central de este texto.

\section{LA POSICIÓN DE JOHN RAWLS: LUGAR Y FUNCIONES DEL TRIBUNAL CONSTITUCIONAL EN LA IDEA DE RAZÓN PÚBLICA}

Arriba mencionamos que la razón por la cual John Rawls se pronuncia sobre la presencia de los tribunales constitucionales que mediante revisión judicial intervienen en la construcción de la democracia contemporánea es con el objeto de ofrecer un régimen político, liberal y democrático, en el cual los asociados en tanto se rijan por una concepción política de justicia puedan alcanzar una vida buena, plural y razonable en un régimen de democracia constitucional. Por lo tanto cree oportuno desarrollar la idea de razón pública ${ }^{15}$ como escenario de par-

14 Bickel, Alexander, The Least Dangerous Branch: The Supreme Court at the Bar of Politics, Indianápolis, 1962

15 Título que dio John Rawls a dos conferencias que leyó en la apertura de Melden Lectures en la Universidad de California entre febrero y marzo de 1990. 
ticipación y autorregulación de los asociados con respecto a la toma de decisiones sobre asuntos que desarrollan las esencias constitucionales. Precisamente en el contexto de lo que significa para Rawls la idea de razón pública aparece con notable claridad el lugar y las funciones del Tribunal Constitucional.

La idea de razón pública es un deber ser sobre la forma en que deberían proceder los hombres como ciudadanos libres e iguales en una sociedad justa y ordenada. Este procedimiento está dirigido a permitir que todos los ciudadanos tengan una participación activa y pública en la construcción y el desarrollo de las esencias constitucionales que son eminentemente circunscritas a lo público ${ }^{16}$ donde es posible la autorregulación. Esto, en aras de lograr la aspiración política del pueblo de autogobernarse a sí mismo de una manera específica y conforme a los postulados constitucionales en los que se desarrolla una cierta concepción política de justicia que a su vez sirve para explicar el contenido de la razón pública por cuanto a través de tal concepción se logran tres cosas:

1. Definir derechos y libertades típicos de los regímenes democráticos;

2. Darle una prioridad especial a esos derechos y libertades, y

16 "La razón pública es la razón de ciudadanos iguales que, como un cuerpo colectivo, ejercen poder político terminante y coercitivo unos respecto de otros aprobando leyes y mejorando su Constitución. Lo primero que hay que observar es que los límites impuestos por la razón pública no rigen para todas las cuestiones políticas, sino sólo para aquellas que implican lo que podríamos llamar 'esencias constitucionales' y cuestiones de justicia básica. Eso significa que solo los valores políticos han de fijar cuestiones fundamentales tales como: quién tiene derecho a voto, o qué religiones hay que tolerar o a quién hay que garantizar una igualdad de oportunidades equitativa o tener propiedades. Estas y otras similares son las cuestiones de que se ocupa la razón pública... Muchas, si no la mayoría, de las cuestiones políticas no tienen que ver con estos asuntos fundamentales... Algunos preguntarán: ¿por qué no declarar que todas las cuestiones respecto de las cuales los ciudadanos ejercen su poder terminante y coercitivo están sujetas a la razón pública? ¿Por qué habría de admitirse la posibilidad de traspasar el alcance de sus valores políticos? He aquí la respuesta: mi objetivo es empezar considerando el caso más fuerte en el que las cuestiones políticas afectan a los asuntos más fundamentales. Si no consiguiéramos respetar aquí los límites puestos por la razón pública, entonces parecería que no necesitamos respetarlos en ninguna otra parte. Si esos límites, en cambio, funcionan aquí, entonces podemos ir más allá y estudiar otros casos" (cursivas añadidas), Rawls, John, Liberalismo político, Barcelona, Crítica, 2004, pp. 249 y 250. 
3. Garantizarle a los asociados los medios necesarios para que se llegue al fin en el que es efectivo el ejercicio de los derechos y las libertades básicos.

Así las cosas, el lugar que ocupa el Tribunal Constitucional con revisión judicial al interior de una sociedad demoliberal donde los hombres y las instituciones están regidos por una concepción política de justicia es el de paradigma de la razón pública en tanto supremo intérprete jurídico de la Constitución. Esta ubicación la expone Rawls en tres pasajes del texto:

i. Una última razón relacionada con la profundidad (del consenso entrecruzado sobre la concepción política de justicia). En un sistema constitucional con revisión judicial, o con revisión llevada a cabo por algún otro cuerpo, los jueces, o los funcionarios en cuestión, necesitarán desarrollar una concepción política de la justicia a la luz de la cual poder interpretar la Constitución y decidir casos importantes. Sólo de este modo pueden declararse constitucionales o inconstitucionales las leyes emanadas de la función legislativa; y solo de ese modo tienen una base razonable para poder interpretar los valores y los criterios que ostensiblemente incorpora la Constitución. ${ }^{17}$

ii. Tenemos que distinguir, sin embargo, entre cómo el ideal de la razón pública rige para los ciudadanos y cómo rige para los varios funcionarios del Estado. Rige en los foros públicos-estatales, y así, para los legisladores, cuando hablan en el hemiciclo parlamentario, y para el Ejecutivo, en sus declaraciones y en sus actos públicos. También rige de un modo especial para el Poder Judicial $\mathrm{y}$, sobre todo, para el tribunal supremo en una democracia constitucional con revisión judicial. Eso se debe a que los jueces tienen que explicar y justificar sus decisiones fundándolas en su interpretación de la Constitución y de las leyes antecedentes relevantes. Puesto que los actos del Legislativo y del Ejecutivo no necesitan justificarse de esa manera, el especial papel de los tribunales de justicia les convierte en el paradigma de la razón pública. ${ }^{18}$

iii. Al empezar (§ 1.2), observé que en un régimen constitucional con revisión judicial, la razón pública es la razón de su tribunal supremo... La razón pública resulta muy adecuada para convertirse en la razón del tribunal supremo cuando éste desempeña su papel de supremo intérprete jurídico, pero no

17 Rawls, John, Liberalismo político, op. cit., nota anterior, p. 198.

18 Ibidem, pp. 250 y 251. 
de intérprete final de la ley suprema; y el tribual supremo es la rama del Estado que sirve como modelo de la razón pública. ${ }^{19}$

El lugar que ocupa el Tribunal Constitucional según John Rawls nos permite concluir que el autor es un exponente del bloque teórico en el que se inscriben quienes ven con buenos ojos el ascenso del Tribunal Constitucional con revisión judicial. Puede entenderse además que si un argumento para justificar que el Tribunal Constitucional ocupe el lugar de máxima expresión de la idea de razón pública es porque sus decisiones deben estar ajustadas al texto escrito constitucional, donde reposan las esencias constitucionales (libertades y derechos básicos); por lo cual se descarta que los jueces sustenten sus decisiones en criterios personales o sus más profundas convicciones, como sustentan algunos críticos que presentamos arriba.

También es oportuno precisar que Rawls no pone al Tribunal Constitucional por encima de las otras ramas del poder público. Considera que están en una igualdad jerárquica y subordinadas al pueblo que es el único y supremo soberano. Simplemente reconoce que su acción en tanto intérprete de la Constitución le otorga una función especial en la consolidación del ordenamiento jurídico y en la defensa por lograr la coherencia entre las prescripciones normativas y la Constitución.

Después de haber dado respuesta a la pregunta por el lugar que ocupa el Tribunal Constitucional para John Rawls (esto es, ser la máxima expresión de la idea de la razón pública), nos proponemos ahora explicar cuáles son las funciones que cumple dicho órgano al interior de una sociedad ordenada, justa y liberal:

i. Dado que Rawls retoma la distinción que hace John Locke entre poder constituyente del pueblo y poder ordinario de los funcionarios del Estado, considera que las leyes emanadas del pueblo son leyes supremas y soberanas; de tal manera que el Tribunal Constitucional a la hora de ejercer revisión judicial debe evitar que dicha ley suprema sea erosionada por mayorías pasajeras o minorías dominantes que blindan sus intereses particulares mediante leyes superiores. 
Si el tribunal asume ese papel y efectivamente lo desempeña, es incorrecto decir que es derechamente antidemocrático. En realidad es antimayoritario respecto de la ley ordinaria, pues un tribunal encargado de la revisión judicial puede declarar inconstitucionales leyes de ese tipo. Sin embargo, la autoridad superior del pueblo lo apoya. El tribunal no es antimayoritario respecto de la ley suprema cuando sus decisiones resultan razonablemente acordes con la constitución misma, con sus enmiendas y con las interpretaciones de ellas políticamente obligadas. ${ }^{20}$

ii. Dar a la razón pública vivacidad y vitalidad en el foro público. Esto se logra en la medida en que el Tribunal Constitucional interpreta el texto constitucional escrito de una manera razonable.

iii. Dotar a la razón pública continuamente de su debido efecto sirviendo como un modelo institucional suyo.

Eso significa que la razón pública es la única razón de que se vale el tribunal. Él es la única rama del Estado que es palmaria y visiblemente criatura de tal razón, y solo de tal razón. Los ciudadanos y los legisladores pueden votar de acuerdo con sus respectivas doctrinas comprehensivas, más abarcantes, cuando las esencias constitucionales y la justicia básica no están en juego; no necesitan justificar mediante la razón pública por qué van a votar como votan, o hacer que sus razones sean consistentes y adecuarlas a una visión constitucional coherente que abarque el espectro global de sus decisiones. Pero el papel de los jueces consiste precisamente en hacer eso y, al hacerlo, no pueden tener otra razón que la pública, ni otros valores que los políticos. Más allá de lo cual no pueden dejarse guiar sino por lo que ellos piensen que exigen los casos, prácticas y tradiciones constitucionales, así como los textos históricamente significativos. Decir que el tribunal es el modelo de la razón pública significa también que es tarea de los jueces intentar desarrollar y expresar, en sus opiniones razonadas, la mejor interpretación de la Constitución que puedan usando su conocimiento de los que exigen la constitución y los precedentes constitucionales. ${ }^{21}$

\section{CONCLUSIONES}

Los hechos bárbaros de la segunda guerra mundial exigieron replantear el asunto típicamente moderno de la rama judicial como un órgano

$20 \quad$ Ibidem, pp. 268 у 269.

21 Ibidem, p. 271. 
residual y minimizado frente a los poderes Legislativo y Ejecutivo. Surge entonces un nuevo discurso filosófico y político donde se sospecha de las mayorías parlamentarias y se espera que a través de la revisión judicial sea posible un filtro veraz con respecto a los posibles excesos a los que pueden conducirnos las mayorías.

Tal acción de los tribunales constitucionales ha sido notoria. En algunos casos históricos ha sido un objeto de control que parece tomar un poder político y jurídico que resulta a su vez carente de control. Este empoderamiento del Poder Judicial ha sido leído por algunos como algo necesario y para otros como algo peligroso. Los exponentes que ven escépticamente este ascenso cuestionan su legitimidad; los pocos controles que recaen sobre dicho órgano y el alcance colegislativo que ha ido logrando con el tiempo.

John Rawls, a la hora de explicar la idea de razón pública, reconoce que el Tribunal Constitucional es su máxima expresión, en tanto sirve como intérprete de las esencias constitucionales que están consagradas en el texto escrito constitucional; de tal manera que todo el ordenamiento jurídico esté orientado por el respeto a unos derechos y libertades básicos con los cuales los asociados pueden ejercer control y limitarse mutuamente.

La ubicación que Rawls le da al Tribunal Constitucional nos permite afirmar que puede inscribirse en la línea de quienes aprueban o consienten el ascenso de los tribunales constitucionales con revisión judicial y de esta manera podemos afirmar que para John Rawls los tribunales que están razonablemente comprometidos a llevar hasta las últimas consecuencias su función de máxime intérprete jurídico de la Constitución, así aparentemente se les acuse como antimayoritarios o arbitrarios, son dinamizadores de la democracia contemporánea.

Una democracia constitucional sobre la cual reposa toda la teoría política liberal de Rawls debe entenderse en un sentido dual de marcada inspiración lockeana. Por un lado está la diferencia entre el poder constituyente y el poder ordinario; por el otro, está la diferencia entre la ley suprema del pueblo y la ley ordinaria del legislador. Con una prevalencia irrestricta de los primeros sobre los segundos.

John Rawls si bien otorga una función especial al Poder Judicial señala enfáticamente que su pretensión en el texto no es ofrecer una defensa de la revisión judicial sino elaborar la idea de razón pública. Reconoce 
que el Poder Judicial es quien mejor le sirve para la elaboración de dicho modelo pero no desconoce que las otras ramas del poder público también están llamadas a participar en el foro público en la construcción de cuestiones constitucionales. No es el Tribunal Constitucional quien hace el derecho. El Tribunal es simplemente el intérprete jurídico y garante de que las esencias constitucionales sean de uso del verdadero y único soberano: el pueblo. De quien emana el poder constituyente y la ley suprema que el Tribunal Constitucional protege pero no restringe. Es el pueblo mismo quien tiene la potestad de modificar, ampliar o restringir el marco de las esencias constitucionales. Eso podría resultar peligroso pero es el riesgo que, a juicio de Rawls, debe asumir toda sociedad típicamente liberal.

\section{BIBLIOGRAFÍA}

HAMilton, Alexis, El Federalista, México, Fondo de Cultura Económica, 1988.

BICKEL, Alexander, The Least Dangerous Branch: The Supreme Court at the Bar of Politics, Indianápolis, 1962.

BoBBIO, Norberto, La teoría de las formas de gobierno en la historia del pensamiento político, México, Fondo de Cultura Económica, 1992.

BRAVO RESTREPO, Luis Alfonso, "Legitimidad del control constitucional y los controles a la Corte Constitucional", Estudios de Derecho, núm. 59, Medellín, julio-diciembre de 2000.

DWORKIN, Ronald, Los derechos en serio, Barcelona, Ariel, 1984.

ELY, John Hart, Democracia y desconfianza, Bogotá, Siglo del Hombre Editores, 1997.

GARCÍA DE ENTERRÍA, Eduardo, La Constitución como norma y el Tribunal Constitucional, 3a. ed., Madrid, Civitas, 2001.

Ginsburg, Tom, Judicial Review in New Democracies: Constitutional Courts in Asian Cases, Cambridge University Press, 2006.

HIRSCHL, Ran, Towards Juristocracy, The Origins and Consequences of the New Constitucionalism, Harvard University Press, 2004.

RAWLS, John, Liberalismo político, Barcelona, Crítica, 2004. 2001. 
Rosenberg, Gerald, The Hollow Hope: Can Courts Bring About Social Change?, Chicago, University of Chicago Press, 1991

Soto PosadA, Gonzalo, Diez aproximaciones al Medioevo, Medellín, UPB, 1999.

ZAGREBELSKY, Gustavo, El derecho dúctil: ley, derechos, justicia, 3a. ed., Madrid, Trotta, 1999. 